\title{
Hazard scenarios for avalanche actions on bridges
}

\author{
Stefan MARGRETH, Walter J. AMMANN \\ WSL Swiss Federal Institute for Snow and Avalanche Research SLF, Flüelastrasse 11, CH-7260 Davos-Dorf, Switzerland \\ E-mail:margreth@slf.ch
}

\begin{abstract}
Engineers require impact scenarios when developing hazard mitigation strategies to protect structures against snow avalanches. Since direct measurements of avalanche impacts on large obstacles are rare, the documentation and post-event analysis of avalanche damages is essential to understand the interaction of avalanches with obstacles. The objective of this paper is to develop hazard scenarios for avalanche actions on bridges, based on a case study of a well-documented avalanche event. The $40 \mathrm{~m}$ long pre-stressed road bridge Ri di Rialp in the Swiss Alps collapsed after being struck by a dense-flow avalanche in 1998. The post-event analysis shows that the controlling hazard scenario was an inclined avalanche impact, not a horizontal impact as one would assume given the topographical situation. Using a failure analysis, an impact angle of $40^{\circ}$ and a minimal impact pressure of $172 \mathrm{kN} \mathrm{m}^{-2}$ were found. Finally the insights are summarized so that engineers can apply the results when designing a bridge at risk from avalanches.
\end{abstract}

\section{INTRODUGTION}

Field measurements of full-scale avalanche impacts on large structures such as bridges or houses are rare. The instrumentation is expensive and often the observed avalanche frequency is too small for good results to be obtained. Avalanche pressures are usually measured with small mechanical or electronic load cells with a diameter of typically $<0.5 \mathrm{~m}$. The sensors are fixed on narrow steel frames (Schaerer, 1973; Schaerer and Salway, 1980; McClung and Schaerer, 1985; Schaer and Issler, 2001). At Mettlenruns, Switzerland, impact pressures have been measured with mechanical sensors on a vertical $2 \times 5 \mathrm{~m}^{2}$ impact wall since 1960. Typical pressures at the wall, mostly of wet-snow avalanches with flow heights $<5 \mathrm{~m}$, were $100-300 \mathrm{kN} \mathrm{m}^{-2}$ with peak pressures up to $650 \mathrm{kN} \mathrm{m}^{-2}$ (Gruber, 1998; Issler, 1999). At the Ryggfonn test site in Norway, impact pressures of up to $540 \mathrm{kN} \mathrm{m}^{-2}$ were measured on a $4.5 \mathrm{~m}$ high, $0.6 \mathrm{~m}$ wide concrete structure (Norem and others, 1985). At the SLF test site Valle de la Sionne in Switzerland in February 1999 the avalanches were larger than assumed for the design of the obstacles. Consequently the $2 \times 5 \mathrm{~m}^{2}$ impact wall was completely destroyed (Dufour and others, 2000).

So far, full-scale impact pressure measurements on large bridges have been made only twice. In Switzerland in 1984 the bearings of the new Rorbach tunnel bridge with a span of $88 \mathrm{~m}$ were instrumented with load cells, after the bridge was destroyed by a powder-snow avalanche (Margreth and Ammann, 2000). In 1996 the measuring installations were closed down because the accuracy of the load cells became questionable. No large avalanche event occurred during the 12 year operation period. In Austria the $80 \mathrm{~m}$ long Grosser Gröben tunnel bridge was instrumented with several pressure plates (Issler, 1999). Since it began operating in 1990, no large avalanche has been recorded here either.

In summary, there are few experimental data available from instrumented field sites concerning avalanche impact pressures on large obstacles such as bridges. Consequently, the documentation of bridges impacted by avalanches, and the back-calculation of pressures, is perhaps the only method that can be used at present to improve our knowledge of the interaction between avalanches and bridges. The objective of this paper is to investigate the destruction of the bridge Ri di Rialp in the Swiss Alps as a case study from which general hazard scenarios for avalanche actions on bridges can be developed.

\section{FAILURE ANALYSIS}

A structural failure occurs if the induced stress - in this case from an avalanche impact - is larger than the loadbearing capacity of a cross-section. In a failure analysis, the ultimate load-bearing capacity of the failed bridge cross-section is first calculated by using the material and section properties and a resistance model. The material properties can be evaluated by laboratory testing; the geometry and section properties can be taken from the documentation of the structure. Different loading cases in which the load distribution, influence area and impact angle vary must be defined. Absolute values for the impact pressure are found by comparing the resulting stress in the investigated cross-section to the computed resistance. It is important to emphasize that, compared to the evaluation of the structural resistance, there is great uncertainty in defining the correct loading case. In addition, the calculated pressures can be cross-checked by computing avalanche impact in relation to avalanche speed, flow depth and density. Due to lack of information (e.g. on fracture depth or avalanche density), the reliability of the computed avalanche impact pressures is also limited. Good failure analysis results can be achieved if a structure is not completely destroyed and if the ultimate resistance can be computed with a simple, reliable model. Completely destroyed structures give minimal pressure values, and undamaged structures give maximal 


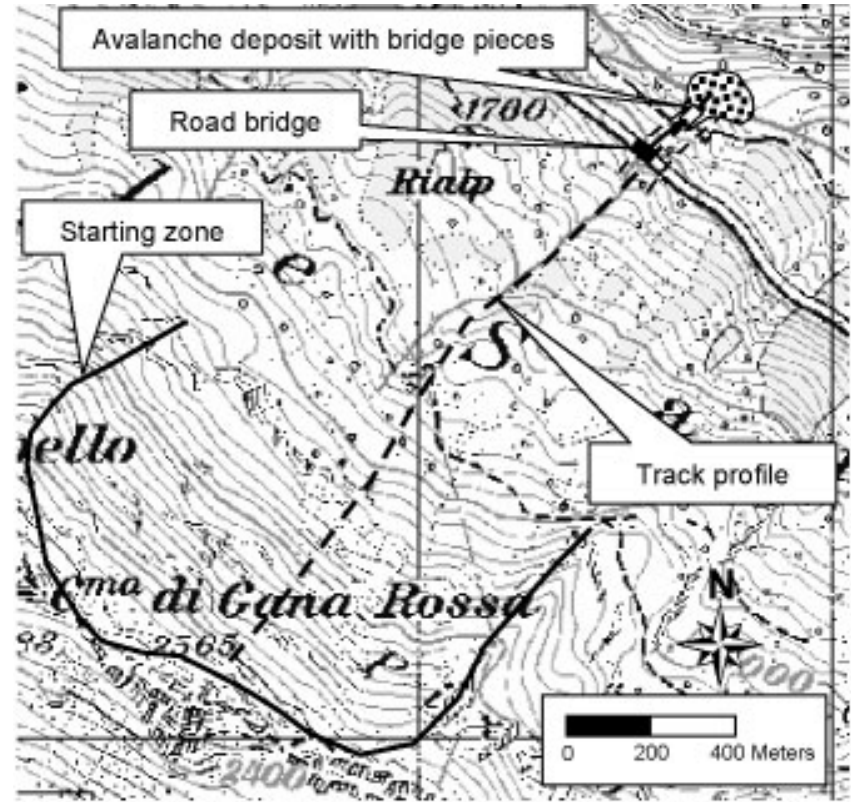

Fig. 1. Overview map of road bridge Ri di Rialp, Lukmanier Pass, Switzerland.

pressure values. Additional information concerning the avalanche impact and loading distribution can be found by analyzing the extension and geometry of avalanche deposits and damage to adjacent vegetation or terrain.

\section{GALGULATION OF AVALANCHE IMPACT}

Avalanche impact pressures are a function of the type of avalanche (powder or flowing) and also the size and shape of the structure (large, small, angular, circular, etc.). For engineering purposes, empirical equations are used to predict impact pressures (Salm and others, 1990). These originate in fluid dynamics. In the case study, the impact pressures will be calculated as follows. The perpendicular impact pressure from a dense-flow avalanche on a large rigid obstacle, which deviates the avalanche flow by the angle $\alpha$, is calculated by:

$$
p_{\mathrm{N}}=\rho v^{2} \sin ^{2} \alpha,
$$

where $p_{\mathrm{N}}$ is the pressure in $\mathrm{N} \mathrm{m}^{-2}$ perpendicular to the impacted surface, $\rho$ is the avalanche flow density in $\mathrm{kg} \mathrm{m}^{-3}$ and $v$ is the avalanche velocity in $\mathrm{ms}^{-1}$. A flow density of $300 \mathrm{~kg} \mathrm{~m}^{-3}$ is usually used for pressure calculations in the avalanche run-out zone. Along the track the flow densities are assumed to be smaller, but reliable density measurements are not yet available. By analyzing impact pressure measurements McClung and Schaerer (1985) determined average flow densities of 125 and $195 \mathrm{~kg} \mathrm{~m}^{-3}$ for dry and wet avalanches, respectively. The friction parallel to the obstacle is:

$$
p_{\mathrm{S}}=\mu p_{\mathrm{N}},
$$

where $p_{\mathrm{S}}$ is the specific friction in $\mathrm{N} \mathrm{m}^{-2}$ and $\mu$ is a friction coefficient typically varying between 0.3 and 0.4 . The total influence height on a large object is calculated according to:

$$
d_{\mathrm{tot}}=d+\frac{v^{2}}{2 g \lambda}
$$

in which $d_{\mathrm{tot}}$ is the total influence height in $\mathrm{m}, d$ is the original avalanche flow depth in $\mathrm{m}$ and $v^{2} / 2 g \lambda$ is the run-up height, where $v$ is the avalanche velocity in $\mathrm{ms}^{-1}, \lambda$ is an empirical factor taking into account the loss of momentum during the impact and $g$ is the acceleration of gravity. For light, dry snow avalanches $\lambda$ is chosen to be 1.5, and for dense-flow avalanches 2-3 (Salm and others, 1990). The pressure is assumed to be constant over the flow depth $d$ and from the top of the flow to the total influence height, decreasing linearly to zero.

The resultant impact force on a small obstacle which a dense-flow avalanche can completely flow around, such as a bridge column, is:

$$
P=c F \rho v^{2} / 2
$$

where $P$ is the impact force in $\mathrm{N}, c$ is the drag coefficient, $F$ is the cross-sectional area normal to the flow direction and $\rho v^{2} / 2$ is the dynamic pressure. For a rectangular cross-section, $c$ is 2 , and for a circular cross-section $c$ is 1 . If the avalanche is composed of solid, sliding blocks then the impact pressure can be substantially larger than calculated by Equation (4).

Equation (4) can be adapted for the pressure calculation originating from a powder-snow avalanche which is similar to the aerodynamic wind pressure except for the higher density of the powder cloud. Typical densities $\rho$ of fully developed powder-snow avalanches are in the range $1-10 \mathrm{~kg} \mathrm{~m}^{-3}$. The drag coefficient $c$ depends on characteristics of the structure and of the stream function. Values of $c$ are tabulated in most design standards and codes (e.g. Swiss code SIA 160 (1989)). Note that there are not only pressure forces but also suction forces on the surfaces parallel to the avalanche flow and on the leeward side.

\section{GASE STUDY: GATASTROPHIC FAILURE OF THE ROAD BRIDGE RI DI RIALP}

\subsection{Technical data of the bridge}

The destroyed two-lane road bridge is situated on the south side of Lukmanier Pass in the central part of the Swiss Alps at $1600 \mathrm{~m}$ a.s.l. (Fig. 1). The $40 \mathrm{~m}$ long bridge spans a Vshaped gully with a maximal distance above the ground of $16 \mathrm{~m}$. The bridge was constructed in 1972. It was designed for dead loads, traffic and snow loads; avalanche loads were not considered. The static system is a simply supported beam. The main structural element of the pre-stressed concrete bridge is a $2.3 \mathrm{~m}$ high, $4.6 \mathrm{~m}$ wide box girder. The total width of the deck slab is $8.80 \mathrm{~m}$ (Fig. 2). The total weight of the superstructure is $5300 \mathrm{kN}$. The catastrophic failure was analyzed by the SLF (Jungwirth, 1999; Margreth and Ammann, 2000).

\subsection{Avalanche situation and destruction of the bridge}

The unconfined avalanche starting zone has a mean inclination of $35^{\circ}$ and is situated on the northeast slope of the Cima di Gana Rossa (Figs 1 and 3a). It extends from 2460 to $2110 \mathrm{~m}$ a.s.l. with a maximal width of $1000 \mathrm{~m}$. The avalanche volume may be $>500000 \mathrm{~m}^{3}$. The maximal width of the avalanche is $500 \mathrm{~m}$ at the bridge site. The main part of the flow is concentrated in a $40 \mathrm{~m}$ wide $\mathrm{V}$-shaped gully which was spanned by the bridge. The mean slope of the avalanche track at the bridge site is $20^{\circ}$. There is a sudden change in inclination $10 \mathrm{~m}$ above both ends of the bridge. The slope just above the road drops nearly vertically. The deposition zone begins $100 \mathrm{~m}$ below the bridge (Fig. 4).

The avalanche was released on 11 April 1998 after a heavy snowstorm. Under its impact, the bridge girder col- 


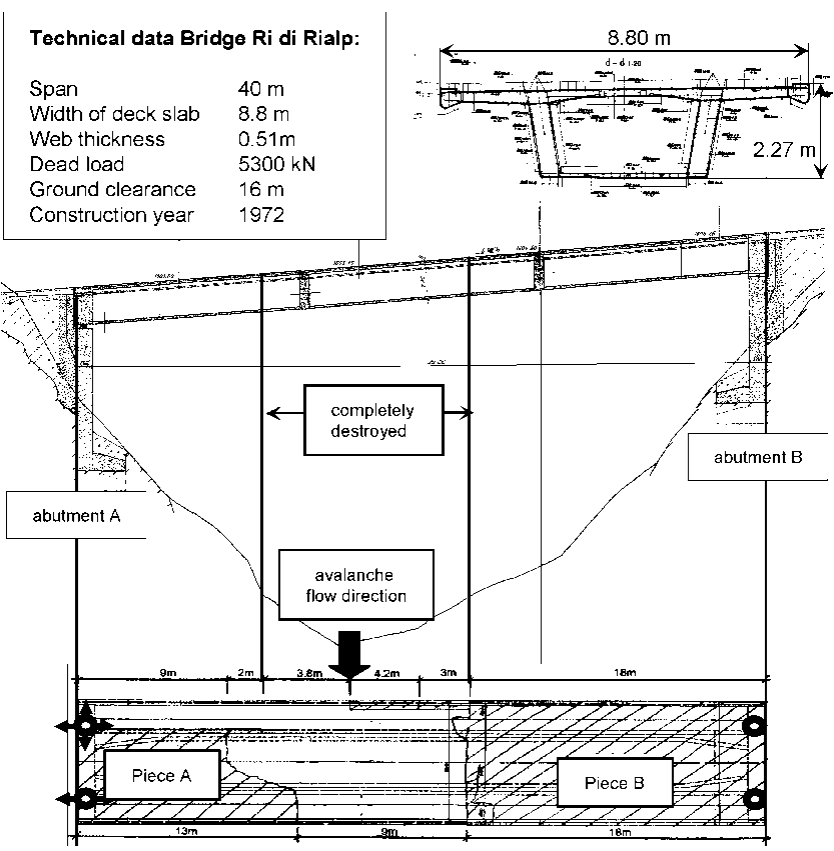

Fig. 2. Technical data, sections and bearing layout of bridge Ri di Rialp.

lapsed in two pieces which remained connected by the unbroken tendons only, and descended $120 \mathrm{~m}$. No detailed data of the avalanche event could be gathered since the Lukmanier pass road was permanently closed in winter and the destruction was only discovered some days after the event. During the 3 days before the catastrophic failure, nearby snow observation stations measured a total snow-depth increase of $80 \mathrm{~cm}$. Because of the stormy southerly winds it is likely that additional snow masses drifted into the starting zone. The older new-snow layers had not yet consolidated, so the shear failure was probably located in the pre-storm snowpack. A mean fracture depth of $130 \mathrm{~cm}$ was assumed. Damages to the vegetation and guard-rails beside the bridge indicated that the avalanche width was about $120 \mathrm{~m}$ larger than the bridge width and that the highest avalanche inten- sity was in the gully and near abutment A (Figs 2 and 3). The avalanche deposit was estimated to be $100000 \mathrm{~m}^{3}$. Traces and damages observed revealed the avalanche to be a dense-flow avalanche with a small powder part. The return period of the avalanche from 11 April 1998 is estimated to be 30 years.

Since construction in 1972 two much larger avalanches had previously impacted the bridge but, surprisingly, no structural damage was observed in these cases (Fig. 3a).

\subsection{Back-calculation of the destructive avalanche}

Using the avalanche dynamics program AVAL-1D (Christen and others, 2002), a quasi-one-dimensional, hydraulicsbased and depth-averaged continuum model developed at the SLF, the avalanche from 1998 was back-calculated. The exact avalanche release area, the fracture depth and the flow width are unknown and have to be estimated, so the accuracy of the numerical simulation is limited. With a fracture width of $250 \mathrm{~m}$ and a fracture depth of $1.3 \mathrm{~m}$, the initial volume of the avalanche is $160000 \mathrm{~m}^{3}$. Two profiles were calculated in the lower part of the track (Figs 1 and 4): with a canalized flow of $40 \mathrm{~m}$ at the location of the bridge the velocity is $40 \mathrm{~m} \mathrm{~s}^{-1}$ and the flow depth is $6.6 \mathrm{~m}$; for an unconfined flow with a width of $120 \mathrm{~m}$ the velocity is $38 \mathrm{~m} \mathrm{~s}^{-1}$ and the flow depth reduces to $2.7 \mathrm{~m}$. With an assumed flow density of $250 \mathrm{~kg} \mathrm{~m}^{-3}$, the corresponding impact pressures $p_{\mathrm{N}}$ are 400 and $360 \mathrm{kN} \mathrm{m}^{-2}$ respectively.

\subsection{Failure analysis}

An $11 \mathrm{~m}$ long section in the middle of the bridge was completely destroyed, concrete and reinforcement were ripped off and the tendons remained unbroken (Fig. 2). The remaining smaller piece A of the broken girder was $11 \mathrm{~m}$ long. Piece $\mathrm{B}$ was $18 \mathrm{~m}$ long. Shear cracks in the hillside web of the box girder of piece $\mathrm{A}$ indicated that the highest impact loads must have occurred near abutment $\mathrm{A}$. The following failure mechanism was assumed: Due to the avalanche impact the ultimate load-bearing capacity of the girder was exceeded in the centre of the completely destroyed section at a dis-
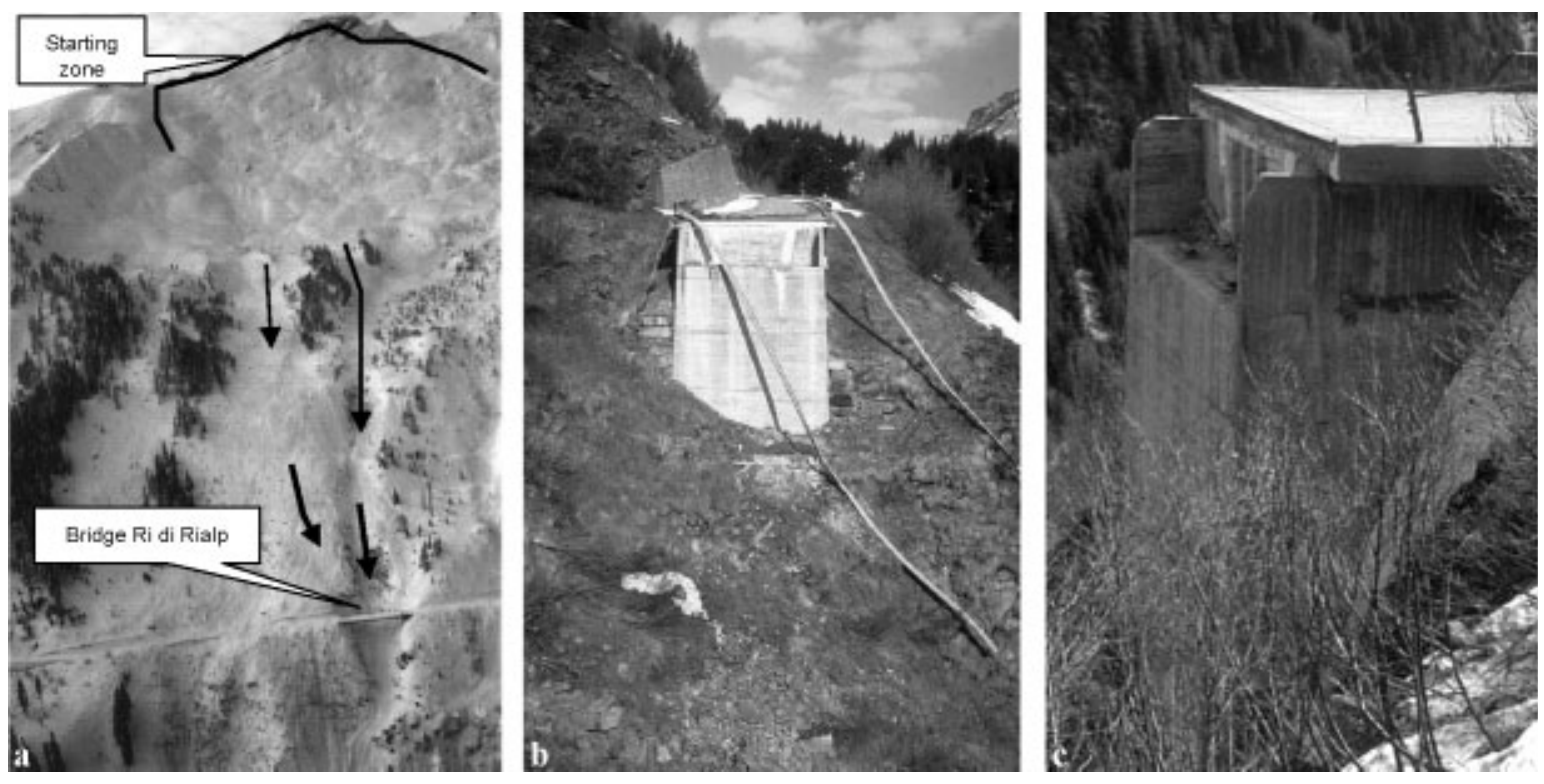

Fig. 3. (a) Overview of avalanche track and bridge Ri di Rialp, avalanche from Fanuary 1994. (b) Destroyed bridge with unfastened rail guards: view to abutment B, May 1998. (c) Abutment A with undamaged wing walls, May 1998. 


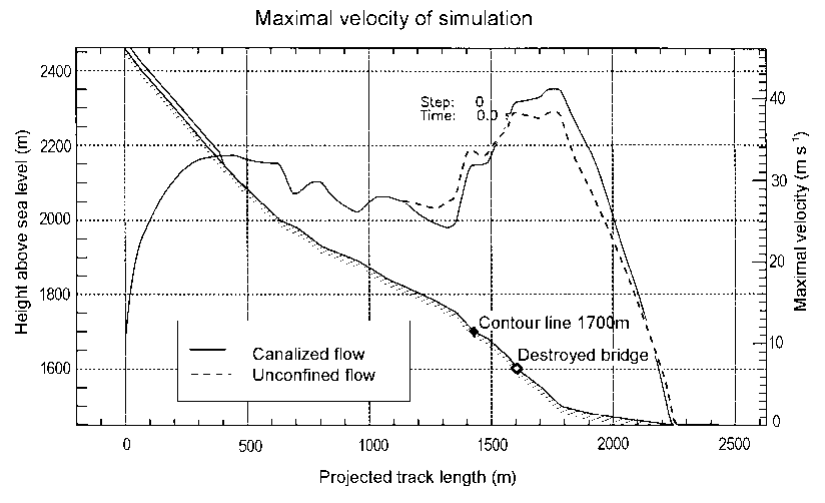

Fig. 4. AVAL-1D track and velocity profile of the back-calculated destructive avalanche from 11 April 1998.

tance of $15.5 \mathrm{~m}$ from abutment A. Consequently, a plastic hinge was formed, and the simply supported girder became unstable and collapsed. Pieces A and B could then be pulled easily off the abutments. We assume that piece A was ripped from the abutment at a high velocity and then pulled down piece $B$. The fall of piece $B$ was damped a little by piece A, which could explain why piece $B$ sustained less damage (Fig. $3 \mathrm{~b})$. Finally, the ruptured girder, comprising the two pieces connected by the tendons only, was swept down the track by the avalanche. Erosion traces in the gully were visible. Damage to the abutments and the bearings was crucial for the evaluation of the failure mode. The thin lateral abutment wing walls showed no signs of damage (Fig. 3c). Therefore, it could be excluded from the analysis that the bridge girder was laterally pushed from the abutments, even though the topography might have favoured a horizontal impact with a subsequent lateral displacement of the bridge girder as the controlling hazard scenario. Concrete spallings at the leading edge of abutments $\mathrm{A}$ and $\mathrm{B}$ clearly indicate that there was no lateral displacement and that the girder slipped in full over these edges. The following two criteria were considered in determining the ultimate failure load:

\section{Criterion 1: ultimate bending moment of the bridge girder}

The computation of the ultimate bending moment of the completely destroyed bridge girder was more complex than initially assumed. Parameters like unsymmetrical bending, second-order stability problems, the assumption of plane sections, insufficient composite of the shear reinforcement or the bondage of the pre-stressed tendons are of importance. The material properties of the concrete and the reinforcement were evaluated in a material-testing laboratory. After 27 years the compressive strength of the concrete was $82 \mathrm{~N} \mathrm{~mm}^{-2}$, the mean tensile strength of the reinforcement was $505 \mathrm{~N} \mathrm{~mm}^{-2}$ and the mean tensile strength of the tendons was $1602 \mathrm{~N} \mathrm{~mm}^{-2}$. The section properties were taken from the design documentation of the bridge. The biaxial bending resistance of the bridge was calculated for the cross-section in the middle of the totally destroyed girder section using the cross-section analysis software FAGUS 3 (Cubus AG, 1997). The tendons were assumed to be partially bonded. The ultimate bending moment is shown in Figure 5 in a polar interaction diagram as a function of the impact angle. The bending moment produced by the dead loads was subtracted from the ultimate moment. For an impact angle of $90^{\circ}$, the failure moment $M_{y}$ is $55000 \mathrm{kN} \mathrm{m}$, and
9080

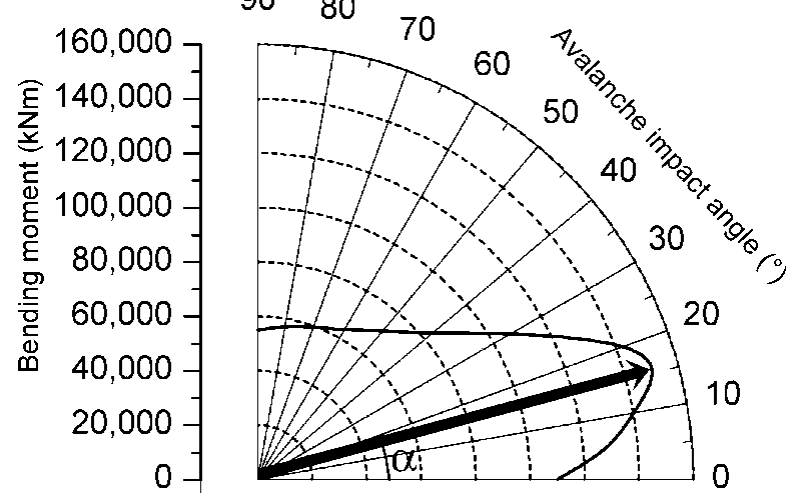

Ultimate bending moment of the bridge girder (criterion 1)

Fig. 5. Polar interaction diagram of the ultimate bending moment of the bridge girder at a distance of $15.5 \mathrm{~m}$ from abutment $A$ in relation to the avalanche impact angle $\alpha$.

for an impact angle of $0^{\circ}$ the failure moment $M_{z}$ is $110000 \mathrm{kNm}$. The ultimate failure moment of $153000 \mathrm{kN} \mathrm{m}$ was found for an impact angle of $15^{\circ}$. The bridge girder investigated is less resistant to vertical than to horizontal forces. The ultimate bending moment gives a lower bound for the avalanche impact load.

\section{Criterion 2: ultimate lateral force of the bridge bearings}

The bridge bearings transfer forces to the abutments. In the present situation the bridge did not slide laterally. The lateral resistance of the bridge bearings was greater than the horizontal load due to the avalanche impact and represents an upper bound for the horizontal component of the avalanche load. At abutment A there is one fixed bearing and one free-sliding bearing. The bearing layout is given in Figure 2. The ultimate lateral force depends on the shear resistance of the guiding gib of the fixed bearing and the friction resistance of the bearing with free translation perpendicular to the bridge axis. Two friction coefficients were applied. Firstly, a friction coefficient of 0.1 was chosen between the stainless-steel bearing and the PTFE (polytetrafluoroethylene) sliding surface and, secondly, a relatively conservative value of 0.3 corresponding to steel bearing on steel, representing a heavily damaged PTFE sliding surface. For a horizontal loading, the ultimate lateral force of the bearings at abutment A is 1700 and $2300 \mathrm{kN}$, respectively. For larger impact angles, the ultimate lateral force increases because of the higher friction force.

\subsection{Hazard scenario and loading models}

\section{Longitudinal loading model}

The bridge Ri di Rialp spanned the V-shaped gully at a height varying between 3 and $16 \mathrm{~m}$. We assumed that the main impact was caused by a dense-flow avalanche near abutment A. In the centre of the bridge the impact of the dense part is much smaller because the ground clearance there is larger compared to the flow depth, including the height of previous snow deposits. The impact pressure of a simultaneous powder-snow avalanche might be much smaller but cannot be completely neglected. Based on the local topography, the observed avalanche traces and the failure analysis conducted, a triangular load distribution of the dense avalanche was chosen (Fig. 6). The maximal pressure 


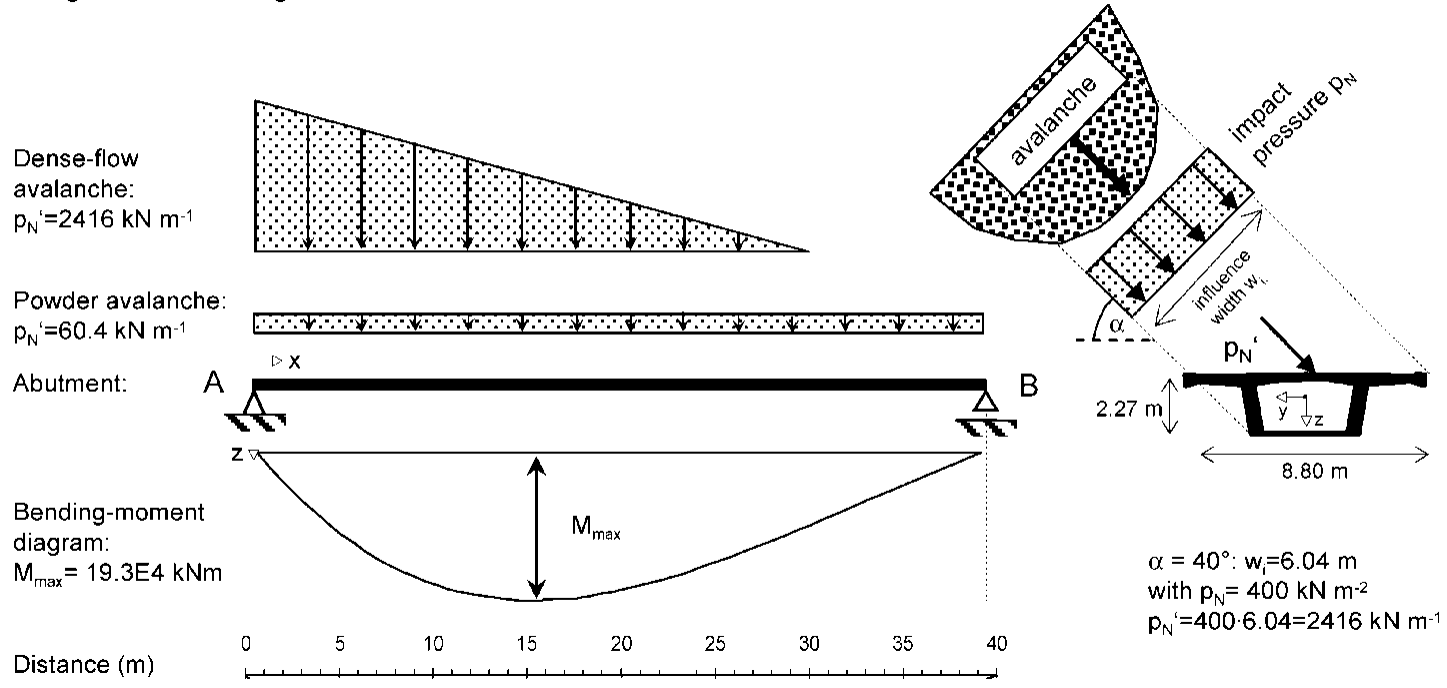

Fig. 6. Longitudinal and lateral loading model of the destroyed bridge Ri di Rialp.

is at abutment $\mathrm{A}$, and the pressure decreases linearly towards the centre of the bridge. The additional pressure of the powder part was assumed to be $2.5 \%$ of the dense part and evenly distributed over the whole bridge span. The length of the triangular load of $30 \mathrm{~m}$ was determined such that the maximal bending moment was located $15.5 \mathrm{~m}$ from abutment $\mathrm{A}$ in the middle of the completely destroyed section.

\section{Lateral loading model}

The avalanche impact angle on the bridge girder is important. If the impact angle is $0^{\circ}$ then the avalanche hits the $2.27 \mathrm{~m}$ high web of the box girder. If, on the other hand, the impact angle is $90^{\circ}$ then the avalanche hits the $8.8 \mathrm{~m}$ wide deck slab. For an inclined impact, the calculation of the impact force due to the deflection of the avalanche flow is more complex. We applied a simplified lateral loading model assuming a constant load distribution concentrated in the centre of shear of the bridge cross-section to neglect the problem of torque (Fig. 6). The influence width was set equal to the width of the shadow of the bridge cross-section perpendicular to the flow direction. For an impact angle of $40^{\circ}$ the corresponding influence width is $6.04 \mathrm{~m}$. The multiplication of the impact pressure by the influence width gives the triangularly distributed line load.

\subsection{Results and interpretation}

With the longitudinal and lateral loading model described above, the calculated ultimate bending moment and lateral force can be converted to a maximal value of the triangularly distributed line load at abutment $\mathrm{A}$ and consequently to the impact pressure in relation to the impact angle (Fig. 7; Table 1).

According to criterion 1 (ultimate bending moment of the bridge girder), for an impact angle of $0^{\circ}$ an impact pressure of $606 \mathrm{kN} \mathrm{m}^{-2}$ is sufficient for a failure. This pressure corresponds to an avalanche speed estimated at $45 \mathrm{~m} \mathrm{~s}^{-1}$. As the bridge did not fail horizontally, we conclude that the speed of the destructive avalanche was $<45 \mathrm{~m} \mathrm{~s}^{-1}$. Comparison of the impact pressures back-calculated with AVAL-1D, of 360 and $400 \mathrm{kN} \mathrm{m}^{-2}$, with the impact pressure corresponding to the ultimate bending moment of the bridge girder shows that the impact angle is at least $22^{\circ}$. For an impact angle of $60^{\circ}$ a minimum impact pressure of $100 \mathrm{kN} \mathrm{m}^{-2}$ would destroy the bridge. The corresponding avalanche speed is $18 \mathrm{~m} \mathrm{~s}^{-1}$.

The interpretation of criterion 2 (ultimate lateral force of the bridge bearings) is more complex. Because the bridge girder does not slide laterally from the abutments at an impact pressure of the back-calculated 360 and $400 \mathrm{kN} \mathrm{m}^{-2}$ respectively, the minimal impact angle, according to Figure

Table 1. Impact pressure at abutment A for the failure of the bridge Ri di Rialp in relation to the impact angle $\alpha$

\begin{tabular}{|c|c|c|c|c|c|c|c|}
\hline \multirow[b]{3}{*}{ Impact angle $\alpha$} & \multirow{2}{*}{\multicolumn{3}{|c|}{ Criterion 1: ultimate bending moment of bridge girder }} & \multicolumn{4}{|c|}{ Criterion 2: ultimate lateral force of bridge bearings } \\
\hline & & & & \multicolumn{2}{|c|}{ Friction coefficient 0.1} & \multicolumn{2}{|c|}{ Friction coefficient 0.3} \\
\hline & $\begin{array}{l}\text { Maximum of } \\
\text { triangular line load }\end{array}$ & Impact pressure & $\begin{array}{l}\text { Avalanche speed } \\
\left(\rho=250 \mathrm{~kg} \mathrm{~m}^{-3}\right)\end{array}$ & $\begin{array}{c}\text { Maximum of } \\
\text { triangular line load }\end{array}$ & Impact pressure & $\begin{array}{c}\text { Maximum of } \\
\text { triangular line load }\end{array}$ & Impact pressure \\
\hline$\circ$ & $\mathrm{kN} \mathrm{m}^{-1}$ & $\mathrm{kN} \mathrm{m}^{-2}$ & $\mathrm{~ms}^{-1}$ & $\mathrm{kN} \mathrm{m}^{-1}$ & $\mathrm{kN} \mathrm{m}^{-2}$ & $\mathrm{kN} \mathrm{m}^{-1}$ & $\mathrm{kN} \mathrm{m}^{-2}$ \\
\hline 0 & $>1377$ & $>606$ & $>45$ & $<144$ & $<64$ & $<197$ & $<87$ \\
\hline 30 & $>1352$ & $>270$ & $>30$ & $<177$ & $<35$ & $<275$ & $<64$ \\
\hline 40 & $>1041$ & $>172$ & $>24$ & $<206$ & $<34$ & $<344$ & $<74$ \\
\hline 60 & $>793$ & $>100$ & $>20$ & $<349$ & $<44$ & $<820$ & $<150$ \\
\hline 80 & $>713$ & $>82$ & $>18$ & $<1920$ & $<219$ & - & - \\
\hline 90 & $>688$ & $>78$ & $>17$ & - & - & - & - \\
\hline
\end{tabular}




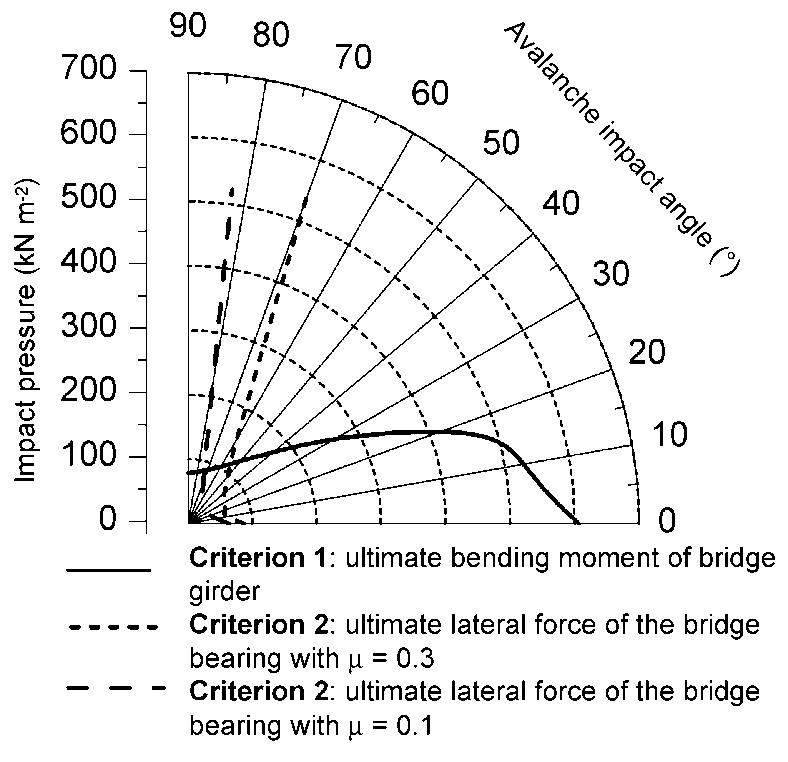

Fig. 7. Polar diagram of the impact pressure in relation to impact angle $\alpha$ at abutment A for failure criteria 1 and 2.

7 , is $68^{\circ}$ for a friction coefficient of 0.3 , and $82^{\circ}$ for a friction coefficient of 0.1 . For an impact angle of $30^{\circ}$, the maximum impact pressures for the bridge not sliding laterally are 35 and $64 \mathrm{kN} \mathrm{m}^{-2}$ respectively. With these pressure values, the bridge girder will not be destroyed. For a failure of the bridge girder, the minimal impact angle is $53-73^{\circ}$ (Fig. 7). For this topographical situation these impact angles seem rather large. The assumed resistance model for the ultimate lateral force on the bridge bearings seems rather conservative. Therefore, the impact angle was verified by calculating the parabolic trajectory when the avalanche jumps over the terrain edge above abutment $\mathrm{A}$. For a slope of $20^{\circ}$ above the edge, a vertical height difference of $9 \mathrm{~m}$ and an avalanche speed of $40 \mathrm{~m} \mathrm{~s}^{-1}$, the resulting impact angle on the bridge plate is $38^{\circ}$. This simple calculation also indicates that criterion 2 overestimates the impact angle. Based on these results, we assume that the impact angle of the destructive avalanche was approximately $40^{\circ}$.

We conclude that an inclined impact of the avalanche estimated to be $40^{\circ}$ destroyed the bridge girder. For this impact angle, a minimal impact pressure of $172 \mathrm{kN} \mathrm{m}^{-2}$ and an avalanche speed of $24 \mathrm{~m} \mathrm{~s}^{-1}$ were sufficient for a failure. The back-calculation with AVAL-1D gave an impact pressure of $360-400 \mathrm{kN} \mathrm{m}^{-2}$. Thus, we assume that the impact pressure of the avalanche was higher by at least a

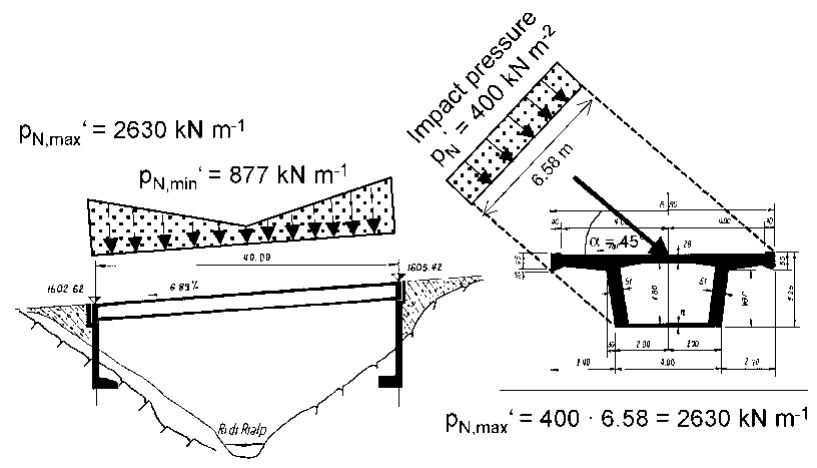

Fig. 8. Hazard scenario and loading model for a reconstruction of bridge Ri di Rialp.
Dense-flow

avalanche

normal load and lateral friction load

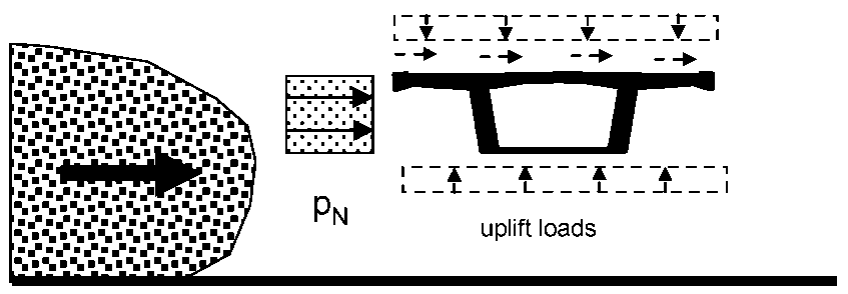

Fig. 9. Hazard scenario 1: horizontal impact of a dense-flow avalanche on a bridge.

factor of two than that calculated from the minimal ultimate bending moment of the bridge girder.

\subsection{Hazard scenario for a reconstruction of the bridge}

The analysis shows that the inclined impact is the determining hazard scenario for the bridge. The flow width was much larger than the width of the V-shaped gully; the highest avalanche impacts occur at both abutments (Fig. 8). In the middle of the bridge, the avalanche impact is smaller because the existing ground clearance is much higher compared to the flow depth. The redesign should account for impact pressures of $400 \mathrm{kN} \mathrm{m}^{-2}$ at the abutments and approximately $133 \mathrm{kN} \mathrm{m}^{-2}$ in the centre of the bridge. These pressures correspond to an estimated return period of 30 years. An impact angle of $45^{\circ}$ seems to be appropriate. The resulting maximal bending moment is $292000 \mathrm{kN} \mathrm{m}$ which is much higher than the ultimate bending moment of the destroyed bridge, $77000 \mathrm{kN} \mathrm{m}$ (Fig. 5). Between 1999 and 2002, the destroyed bridge Ri di Rialp was replaced by an adjustment of the road alignment and protected with an avalanche shed.

\section{PROPOSED HAZARD SCENARIOS FOR AVALANGHE ACTIONS ON BRIDGES}

The definition of universal hazard scenarios for avalanche actions on bridges is difficult, as the topographical situation and the bridge layout are often unique. Therefore each situation must be checked individually. For the design of bridges endangered by avalanches, the following criteria are important:

Topographical situation: The local topography, the position and the geometry of the bridge have considerable influence on the effect of an avalanche. A flat topography, a large ground clearance and a bridge design with few columns is favourable. Steep and narrow V-shaped gullies are often unfavourable for bridges because the discharge cross-section is small, meaning that the flow depths are large and the avalanche can impact the bridge girder diagonally. In such situations the abutments are usually more at risk than the centre of the bridge itself, because the avalanche snow can climb the borders of the gully.

Layout of the bridge: When a bridge needs to be built in avalanche-prone terrain, the areas with the highest impacts should be avoided. Important points are the span, the ground clearance and the geometry of the cross-section of the bridge girder. In the influence area of avalanches, simple and robust slab bridges should be preferred to, for 


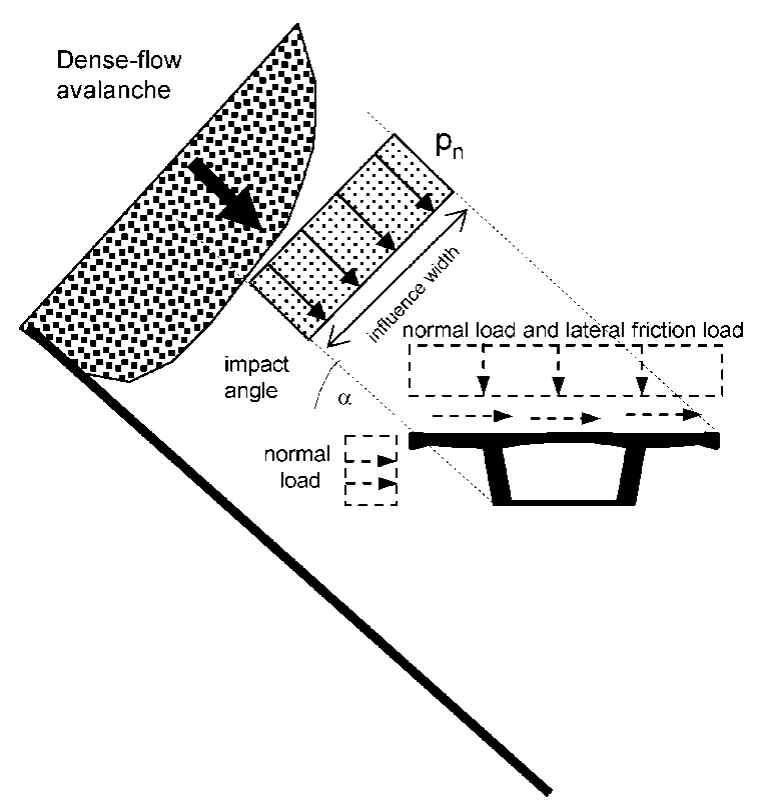

Fig. 10. Hazard scenario 2: inclined impact of a dense-flow avalanche on a bridge.

example, cable-stayed or truss bridges. The columns should be positioned in such a way that a blockage of the avalanche flow is unlikely and the width of the column cross-section normal to the avalanche is as small as possible.

Avalanche situation: Avalanche characteristics such as type or volume are important. Valuable information can often be derived from the avalanche history. With avalanchedynamics calculations, the avalanche speed, pressure and flow depth can be determined. The flow width, flow direction and geometry of the avalanche deposit have to be assessed by analysis of the topography and vegetation. The possibility of multiple events is also important. In addition, point loads arising from dense material such as broken trees or stones must be considered.

Similar to avalanche sheds (ASTRA and SBB, 1994), for the normal design situation (working loads) for avalanche action on bridges we suggest an avalanche return period of 30 years, and for the accidental design situation (failure loads) a return period of 100-300 years. In the normal design situation, the design value is given by multiplication of the calculated avalanche pressure by a load factor (e.g. 1.5 in Swiss code SIA 160 (1989)). In the accidental design situ-

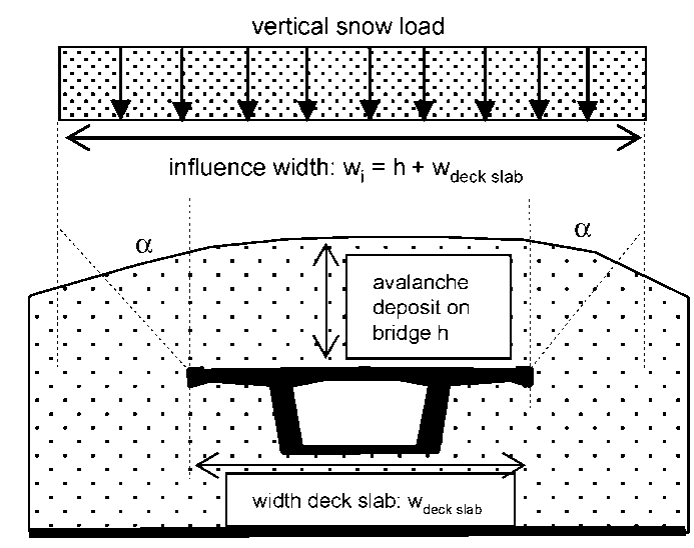

Fig. 11. Hazard scenario 3: avalanche deposit on bridge.

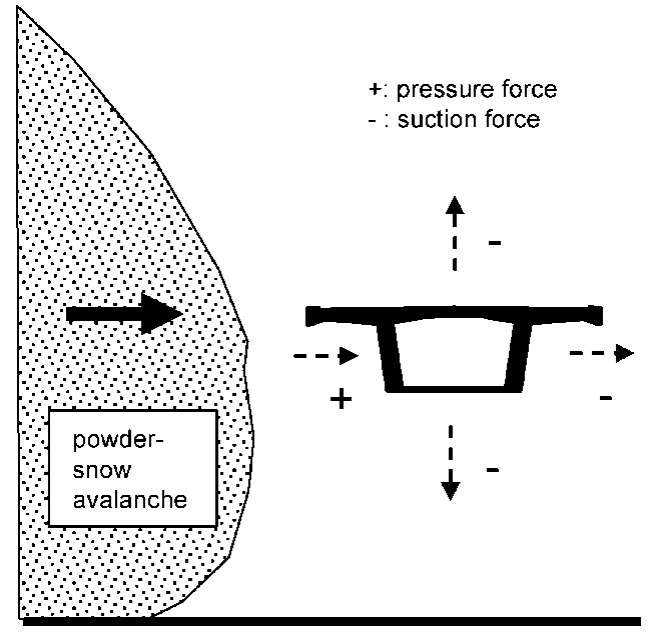

Fig. 12. Hazard scenario 4: impact of a powder-snow avalanche on a bridge.

ation, the design value corresponds to the calculated avalanche pressure.

The most relevant hazard scenarios for avalanche actions on structures are given below. The longitudinal distribution of the impact loads is not given, as it depends mainly on the avalanche and topographical situation.

\section{Hazard scenario 1: horizontal impact of a dense-flow avalanche (Fig. 9)}

The avalanche impacts the bridge girder horizontally. The topography is mostly flat. If the flow depth is larger than the ground clearance, normal and friction loads must also be expected on the bridge deck. Additional uplift loads on the bridge girder estimated at $50 \%$ of the horizontal impact loads can occur. If the flow depth of the normal design situation and, in addition, the height of previously deposited snow multiplied by a safety factor of 1.5 is smaller than the ground clearance, horizontal impact loads can be neglected. The topography at the abutments in particular must be checked. Often an avalanche can run up the side slopes of a gully to be higher than calculated if the local cross-section is reduced by the abutments or if the flow direction is curved.

\section{Hazard scenario 2: inclined impact of a dense-flow avalanche (Fig. 10)}

The avalanche impacts the bridge girder diagonally at the angle $\alpha$, which requires a steep track in most situations. The bridge girder is loaded vertically as well as horizontally. There are two ways of calculating the resultant impact load. The impact pressure can be multiplied by the influence area of the bridge cross-section perpendicular to the flow direction, or the local normal and friction loads on the single surfaces can be summed. Which of these approaches is more accurate is not known.

\section{Hazard scenario 3: avalanche deposit on bridge (Fig. 11)}

The bridge is loaded vertically by the snow mass deposited on the bridge. This hazard scenario must be considered if expected avalanche deposits are higher than the height of the bridge above the ground (e.g. bottom of a narrow valley; short avalanche run-out; small clearance below the 
bridge; multiple avalanche events). For the design, we propose considering an influence width larger than the width of the bridge itself because of edge effects due to the settling of the snowpack. As the ratio of the height of the snow deposit on the bridge to the width of the deck slab increases and with higher clearance below the bridge, a wider influence width should be chosen. In practice, the influence width can be determined as being approximately equal to the width of the deck slab plus the height of the snow deposit on the bridge according to de Quervain and Figilister (1953).

\section{Hazard scenario 4: impact of a powder-snow avalanche (Fig. 12)}

The bridge is impacted by the powder-snow cloud (suspension layer). The local distribution of the impact loads can be determined in accordance with wind loads. As the bridge is submerged by the powder-snow avalanche, there are aerodynamic uplift forces. The drag coefficients are tabulated in most design standards and codes. For full protection of a road, tunnel bridges can be used. Powder-snow avalanches can transport trees and stones which can cause high point impacts. Vortices can be expected to produce severe oscillating loads. According to Shen and Roper (1970), oscillating loads induced by powder-snow avalanches can govern the critical design condition for bridges with insufficient damping or stiffness. In such situations an aerodynamic optimization of the bridge design is needed.

The hazard scenarios must be completed with additional loads (e.g. snow loads or live loads), and the structural safety of the bridge must be designed for the expected loads and load combinations. In a safety plan, the hazard scenarios, loads and accepted risks are described. The safety plan is an important tool for monitoring, inspecting and maintaining the bridge. If a new hazard scenario occurs, which was not considered in the design of the bridge (e.g. blocking of the ground clearance with a first avalanche deposit, creating the risk of a second avalanche), safety can often be ensured by temporary measures.

\section{CONGLUSIONS AND OUTLOOK}

The analysis of the collapsed bridge Ri di Rialp concluded that the determining hazard scenario was an inclined avalanche impact, not a horizontal impact as one would assume given the topographical situation. Using a failure analysis, an impact angle of $40^{\circ}$ and a minimal impact pressure of $172 \mathrm{kN} \mathrm{m}^{-2}$ were found. Back-calculations with the avalanche dynamics model AVAL-1D give impact pressures of $360-400 \mathrm{kN} \mathrm{m}^{-2}$, which are much higher but seem to be reasonable given the amount of destruction. Many assumptions had to be made, so the results of the case study are of limited accuracy. More accurate results might be expected if the static system were simpler and if additional field investigations had been made immediately after the event.

Based on this case study, we conclude that there are still deficiencies in knowledge with regard to avalanche impacts on large structures such as bridges. At present, there is no avalanche impact model which allows the engineer to calculate avalanche impacts on complex structures. The available equations are based on simplified theoretical models. Research should be focused on the following points:
Development of a calculation model for avalanche pressures on large obstacles in relation to the avalanche speed and density. Further research is needed on the flow density of large avalanches.

Calculating the loading distribution on a large object with a complex geometry. Of special interest are the impact height, edge effects and impacts on small obstacles or on countersunk openings and uplift forces.

The instrumentation of bridges with pressure plates and load cells seems worthwhile only if the avalanche frequency is very high. The undertaking of model experiments on small chutes (Tiefenbacher and Kern, in press) with snow or granular materials could improve knowledge of avalanche impacts on large obstacles in an effective way and be a basis for more sophisticated impact models.

\section{REFERENCES}

Bundesamt für Strassen (ASTRA) and Schweizerische Bundesbahnen (SBB). 1994. Richtlinien Einwirkungen auf Lawinenschutzgalerien. Bern, Eidgenössische Drucksachen und Materiaizentrale.

Christen, M., P. Bartelt and U. Gruber. 2002. AVAL-1D: an avalanche dynamics program for the practice. In International Congress INTERPRAEVENT 2002 in the Pacific Rim, 14-18 October 2002, Matsumoto, Fapan. Proceedings. Tokyo, International Research Society INTERPRAEVENT for the Pacific Rim, 715-725.

Cubus A. G. 1997. FAGUS-3 Software. Analyse und Bemessung von Stahl- und Spannbetonquerschnitten. Zürich, Cubus AG.

De Quervain, M. and R. Figilister. 1953. Zum Schneedruckproblem. In Schnee und Lawinen in den Schweizeralpen Winter 1951/52. Davos, Eidgenössisches Institut für Schnee- und Lawinenforschung, 89-98. (Winterbericht 16.)

Dufour, F., U. Gruber, P. Bartelt and W. J. Ammann. 2000. Overview of the 1999 measurements at the SLF test-site Vallée de la Sionne. In ISSW 2000. International Snow Science Workshop, 1-6 October 2000, Big Sky, Montana. Proceedings. Bozeman, MT, American Avalanche Association, 527534.

Gruber, U. 1998. Der Einsatz numerischer Simulationsmethoden in der Lawinengefahrenkartierung: Möglichkeiten und Grenzen. (Ph.D. thesis, Geographisches Institut der Universität Zürich.)

Issler, D., ed. 1999. European avalanche test sites. Overview and analysis in view of coordinated experiments. Eidg. Inst. Schnee- und Lawinenforsch. Mitt. 59.

Jungwirth, J. 1999. Versagensmechanismus und Schadenempfindlichkeit von Bauten in Abhängigkeit von Lawineneinwirkungen - Fallstudie Brücke Ri di Rialp am Lukmanierpass. (Diplomarbeit, Davos, Eidgenössisches Institut für Schnee- und Lawinenforschung.)

Margreth, S. and W. J. Ammann. 2000. Gefährdungsbilder für Lawineneinwirkungen auf Strassenbrucken. Schlussbericht ASTRA, Forschungsaufrag Nr. 96/98, 2445.01.

McClung, D. M. and P. A. Schaerer. 1985. Characteristics of flowing snow and avalanche impact pressures. Ann. Glaciol., 6, 9-14.

Norem, H., T. Kvisterøy and B. D. Evensen. 1985. Measurement of avalanche speeds and forces: instrumentation and preliminary results of the Ryggfonn Project. Ann. Glaciol., 6, 19-22.

Salm, B., A. Burkard and H. Gubler. 1990. Berechnung von Fliesslawinen: eine Anleitung für Praktiker mit Beispielen. Eidg. Inst. Schnee- und Lawinenforsch. Mitt. 47.

Schaer, M. and D. Issler. 2001. Particle densities, velocities and size distributions in large avalanches from impact-sensor measurements. Ann. Glaciol., 32, 321-327.

Schaerer, P. A. 1973. Observations of avalanche impact pressures. USDA For. Serv. Gen. Tech. Rep. RM-3, 51-54.

Schaerer, P. A. and A. A. Salway. 1980. Seismic and impact-pressure monitoring of flowing avalanches. F. Glaciol., 26(94), 179-187.

Schweizerischer Ingenieur- und Architekten-Verein (SIA). 1989. Swiss code Norm 160: Einwirkungen auf Tragwerke. Schw. Ing. Architekt Ver., 6.

Shen, H.W. and A. T. Roper. 1970. Dynamics of snow avalanche (with estimation for force on a bridge). Int. Assoc. Sci. Hydrol. Bull., 15(1), 7-27.

Tiefenbacher, F. and M. Kern. In press. Experimental devices to determine snow avalanche basal friction and velocity profiles. Cold Reg. Sci. Technol. 